\title{
miR-24-3p Is Overexpressed in Hodgkin Lymphoma and Protects Hodgkin and Reed-Sternberg Cells from Apoptosis
}

\author{
Ye Yuan, ${ }^{\dagger \dagger}$ Joost Kluiver, ${ }^{*}$ Jasper Koerts, ${ }^{*}$ Debora de Jong, ${ }^{*}$ Bea Rutgers, ${ }^{*}$ F. Reeny Abdul Razak, ${ }^{*}$ Martijn Terpstra, \\ Boudewijn E. Plaat, ${ }^{\S}$ Ilja M. Nolte, ${ }^{\Uparrow}$ Arjan Diepstra, ${ }^{*}$ Lydia Visser, ${ }^{*}$ Klaas Kok, ${ }^{\ddagger}$ and Anke van den Berg*
}

From the Departments of Pathology and Medical Biology, ${ }^{*}$ Genetics, ${ }^{\ddagger}$ Otorhinolaryngology/Head and Neck Surgery, ${ }^{\S}$ and Epidemiology, ${ }^{\llbracket}$ University of Groningen, University Medical Center Groningen, Groningen, the Netherlands; and the Institute of Clinical Pharmacology of the Second Affiliated Hospital, Harbin Medical University, Harbin, China

\author{
Accepted for publication \\ February 16, 2017. \\ Address correspondence to \\ Anke van den Berg, Ph.D., \\ Department of Pathology and \\ Medical Biology, University \\ Medical Center Groningen, \\ Hanzeplein 1, 9700RB Gronin- \\ gen, the Netherlands. E-mail: \\ a.van.den.berg01@umcg.nl.
}

\begin{abstract}
miRNAs play important roles in biological processes, such as proliferation, metabolism, differentiation, and apoptosis, whereas altered expression levels contribute to diseases, such as cancers. We identified miRNAs with aberrant expression in Hodgkin lymphoma $(\mathrm{HL})$ and investigated their role in pathogenesis. Small RNA sequencing revealed 84 significantly differentially expressed miRNAs in $\mathrm{HL}$ cell lines as compared to germinal center B cells. Three up-regulated miRNAs-miR-23a-3p, miR-24-3p, and miR$27 a-3 p$-were derived from one primary miRNA transcript. Loss-of-function analyses for these miRNAs and their seed family members resulted in decreased growth on miR-24-3p inhibition in three HL cell lines and of miR-27a/b-3p inhibition in one $\mathrm{HL}$ cell line. Apoptosis analysis indicated that the effect of miR-24-3p on cell growth is at least in part caused by an increase of apoptotic cells. Argonaute 2 immunoprecipitation revealed 1142 genes consistently targeted by miRNAs in at least three of four $\mathrm{HL}$ cell lines. Furthermore, 52 of the 1142 genes were predicted targets of miR-24-3p. Functional annotation analysis revealed a function related to cell growth, cell death, and/or apoptosis for 15 of the 52 genes. Western blotting of the top five genes showed increased protein levels on miR-24-3p inhibition for CDKN1B/P27 $7^{\text {kip1 }}$ and MYC. In summary, we showed that miR-24-3p is up-regulated in $H L$ and its inhibition impairs cell growth possibly via targeting CDKN1B/P27 $7^{\mathrm{kip} 1}$ and MYC. (Am J Pathol 2017, 187: 1343-1355; http://dx.doi.org/10.1016/j.ajpath.2017.02.016)
\end{abstract}

Hodgkin lymphoma (HL) is a B-cell-derived lymphoma classified into classic HL (cHL) and nodular lymphocyte predominant HL. ${ }^{1}$ Nodular lymphocyte-predominant HL is a more rare subtype of $\mathrm{HL}$, accounting for approximately $5 \%$ of all cases. ${ }^{2}$ cHL accounts for $95 \%$ of all HL cases and is characterized by a minority of Hodgkin and Reed-Sternberg (HRS) tumor cells, ${ }^{3}$ which have lost their normal B-cell phenotype. ${ }^{4}$ Furthermore, cHL is subclassified according to the morphology of HRS cells and the composition of the cellular background into nodular sclerosis, mixed cellularity, lymphocyte-rich, and lymphocyte-depleted cases. ${ }^{5}$

miRNAs are short noncoding RNA molecules with unique expression patterns in different tissue and cell types. ${ }^{6,7}$ They inhibit gene expression by binding to complementary sequences at the $3^{\prime}$ untranslated region of their target gene transcripts. ${ }^{8}$ One single miRNA can interact with multiple targets. ${ }^{9}$ The first human cancer type reported to be associated with miRNAs was chronic lymphocytic leukemia. ${ }^{10}$ After that, many aberrant miRNA expression patterns have been linked to specific types of cancer. ${ }^{11}$ Depending on their set of target genes, miRNAs can act as oncogenes or tumor suppressor genes. ${ }^{12-14}$

So far, multiple miRNAs are deregulated in B-cell lymphoma and for a subset of them pivotal functions have been shown in the pathogenesis. ${ }^{10,15,16}$ Using small RNA sequencing, Landgraf et $\mathrm{al}^{17}$ generated among others

Y.Y. received a fellowship from the Graduate School of Medical Sciences of the University of Groningen.

Disclosures: None declared. 
miRNA expression profiles of four Epstein-Barr virusnegative cHL cell lines. Van Vlierberghe et $\mathrm{al}^{18}$ identified 12 up-regulated and three down-regulated miRNAs in microdissected HRS cells from nine cHL patients and HL cell lines compared to $\mathrm{CD}_{77^{+}}$germinal center (GC)-B cells Gibcus et $\mathrm{al}^{19}$ determined the miRNA profile of $\mathrm{HL}$ cell lines in comparison to GC-B cell-derived lymphoblastoid cell lines and other B-cell lymphoma cell lines and showed increased expression of the miR-17 92 cluster, miR-16, miR-21, miR-24, and miR-155 in HL. Functional studies in $\mathrm{HL}$ are limited, but for some of the miRNAs their putative role has been established. miR-135a targets JAK2, which leads to reduced Bcl-xL levels in HL. ${ }^{20}$ The miR-17/ 106b seed family targets CDKN1A encoding for the P21 protein and inhibition of this seed family results in a $\mathrm{G}_{1^{-}}$ phase cell cycle arrest. ${ }^{21} \mathrm{HuR}$ and Dicer were shown to be targets of the oncogenic miR-9 and inhibition of miR-9 resulted in higher cytokine production levels. ${ }^{22}$ A significant correlation between miR-124a methylation status and a high-risk international prognostic score was found in HL. ${ }^{23}$

Herein, we established an HL-specific miRNA expression profile using small RNA sequencing and validated differential expression of selected miRNAs. Furthermore, we determined the effects of miR-23a/b-3p, miR-24-3p, and miR-27a/b-3p inhibition on cell growth. To identify target genes regulated by these miRNAs, Ago2 RNA immunoprecipitation (Ago2-RIP) followed by a microarray analysis was performed on four HL cell lines. Targeting of selected Ago2-IP-enriched miR-24-3p-target genes was confirmed using Western blotting.

\section{Materials and Methods}

\section{Culturing of HL Cell Lines and Sorting of GC B Cells}

L540 (nodular sclerosis, T-cell derived), KM-H2 (mixed cellularity), L1236 (mixed cellularity), L428 (nodular sclerosis), and HDLM2 (nodular sclerosis) HL cell lines were cultured in RPMI 1640 medium (Cambrex Biosciences, Walkersville, MD), and the SUPHD1 (lymphocyte depleted) HL cell line was cultured in McCoy 5A medium (Cambrex Biosciences) at $37^{\circ} \mathrm{C}$ in an atmosphere containing $5 \% \mathrm{CO}_{2}$. Culture medium was supplemented with $2 \mathrm{mmol} / \mathrm{L}$ ultraglutamine 1 (Cambrex Biosciences), $100 \mathrm{U} / \mathrm{mL}$ penicillin/streptomycin, and 5\% L428, 10\% L1236, KM-H2, and HDLM2, or $20 \%$ L540 and SUPHD1 fetal bovine serum (Cambrex Biosciences).

GC-B cells were sorted from tonsil tissue samples of three donors aged between 2 and 6 years. Two of the three GC-B cells were purified $>98 \%$ from human tonsils based on expression of $\mathrm{CD} 20^{+} \operatorname{lgD}{ }^{-} \mathrm{CD} 38^{+}$as previously described. ${ }^{24}$ The third sample was magnetic-activated cell sorting purified $>95 \%$ based on expression of $\mathrm{IgD}^{-} \mathrm{CD} 138^{-} \mathrm{CD}^{-} \mathrm{CD}^{-} 0^{+}$. Briefly, a freshly prepared tonsillar cell suspension was prepared and depleted from $\mathrm{IgD}^{+}$(naïve), $\mathrm{CD} 138^{+}$(plasma cells), and $\mathrm{CD}^{+}$( $\mathrm{T}$ cells) using $\mathrm{LD}$ columns and $\mathrm{IgD}^{-}$Biotin $^{+}$
anti-Biotin beads, CD138-beads, and CD3-beads (Miltenyi Biotec, Leiden, the Netherlands). Next, we positively enriched the flow-through fraction for $\mathrm{CD} 10^{+}$cells using CD10 beads and LS columns (Miltenyi Biotec). Purity of the GC-B cell population was confirmed by fluorescence-activated cell sorting using antibodies against CD20, IgD, and CD38 as indicated above. All cells of $\mathrm{CD} 20^{+} \mathrm{IgD}^{-} \mathrm{CD} 38^{+}$were considered to be GC-B cells. The procedures were according to the guidelines of the medical ethics board of the University Medical Center Groningen. Written informed consent was obtained for the use of the tonsil samples from the parents of the children.

\section{RNA Isolation}

RNA was isolated from the total cell lysate fractions and the Ago2-IP fractions of HL cells using miRNeasy mini kit (Qiagen, Hiden, Germany), according to manufacturer's protocol. The RNA concentration was measured by a NanoDrop 1000 Spectrophotometer (Thermo Fisher Scientific Inc., Waltham, MA), and the integrity was evaluated on a $1 \%$ agarose gel.

\section{Small RNA Library Preparation, Sequencing, and Data Analysis}

Small RNA libraries were generated from 2000 ng total RNA using TruSeq Small RNA Sample Preparation Kit and TruSeq small RNA indices (Illumina, San Diego, CA). All RNA samples were analyzed on an Illumina 2000 HiSeq high-throughput sequencing platform. Briefly, $3^{\prime}$ - and $5^{\prime}$ adaptor sequences were removed using the CLC Genomics Workbench (CLC Bio, Cambridge, MA). RNA reads were analyzed with miRDeep version 2.0 (Max Delbrück Center for Molecular Medicine in the Helmholtz Association, https://www.mdc-berlin.de/8551903/en $)^{25}$ and annotated against miRBASE version 21 (http://www.mirbase.org, last accessed November 11, 2014) $)^{26}$ allowing one mismatch. Novel miRNAs were identified using miRDeep. Total read counts were normalized to read counts per million. Read counts for miRNAs with the same mature sequence were merged. For statistical analysis, we included all unique miRNAs with at least 50 read counts in the sum of all seven samples that is the four samples of HL cell lines and the three samples of GC-B cells. The list with both known and novel miRNAs was further analyzed by GeneSpring GX software version 12.5 (Agilent Technologies, Santa Clara, CA). Significantly differentially expressed miRNAs were identified using a moderated $t$-test with BenjaminiHochberg multiple testing correction and a fold change $>4$. The small RNA sequencing data were deposited in the Gene Expression Omnibus database (http://www.ncbi.nlm. nih.gov/geo; accession number GSE92616).

\section{Quantitative Real-Time PCR}

miRNA expression levels were measured using the TaqMan miRNA quantitative PCR assay (Thermo Fisher Scientific 
Inc.) in a multiplexed manner, as described previously. ${ }^{27}$ Based on the small RNA sequencing data, we selected or custom-designed specific TaqMan assays based on the sequence of the most abundant mature miRNA isoforms (Table 1). The miRNA expression levels were normalized to RNU44 (housekeeping gene). Cycle crossing point (Cp) values were determined with the Light Cycler 480 software version 1.5.0 (Roche, Basel, Switzerland). Relative expression levels of miRNAs were determined by calculating $2^{-\Delta \mathrm{Cp}}\left(\Delta \mathrm{Cp}=\mathrm{Cp}_{\text {miRNA }}-\mathrm{Cp}_{\mathrm{RNU} 44}\right)$.

\section{Ago2-RIP-Chromatin IP}

Immunoprecipitation (IP) of the Ago2-containing RISC was performed in four HL cell lines (L1236, L428, L540, and $\mathrm{KM}-\mathrm{H} 2$ ), as described previously using 30 million cells as input. ${ }^{28}$ Microarray analysis was performed as previously described. ${ }^{29}$ Briefly, cRNA was synthesized from total (T) and IP fractions of four HL cell lines. This was followed by a cRNA amplification and labeling step with cyanine 3-CTP (Cy3) or cyanine 5-CTP (Cy5). Equal amounts of Cy3- or Cy5-labeled cRNA were mixed and hybridized on Human Whole Genome Oligo Microarray overnight (SurePrint G3 Custom GE $8 \times 60 \mathrm{~K}$; Agilent Technologies). Quantile normalization of signals was performed using GeneSpring GX software version 12.5 (Agilent). Probes with inconsistent intensities in $\mathrm{Cy} 3$ and $\mathrm{Cy} 5$ replicates and probes not detected in either IP or total fractions were filtered out. For the consistent probes expressed above the background, the average signals for $\mathrm{Cy} 3$ and $\mathrm{Cy} 5$ replicates were used to calculate IP/T ratio for each sample. The Ago2RIP-chromatin IP data were deposited in the Gene Expression Omnibus database (http://www.ncbi.nlm.nih. gov/geo; accession number GSE92615).

\section{Gene Set Enrichment Analysis}

Gene set enrichment analysis (GSEA version 2.2.0; http:// software.broadinstitute.org/gsea/index.jsp) was performed to determine significantly enriched gene sets in Ago2-IP fractions in comparison to total cell lysate fractions. ${ }^{30} \mathrm{~A}$ total of 8430 gene sets were tested based on Molecular Signatures Database version 5.0 (http://software. broadinstitute.org/gsea/msigdb, last accessed January 10, 2017) using a false discovery rate $<0.05$. We focused on gene sets enriched in the IP fraction in at least three of four HL cell lines.

\section{Prediction of Target Genes of miRNAs}

Targetscan version 7.0 (http://www.targetscan.org, last accessed January 10, 2017) was used to generate a list of putative target genes of highly abundant and differentially expressed miRNAs using cumulative weighted context ${ }^{++}$ scores of genes less than or equal to $-0.3 .^{31} \chi^{2}$ test was applied to assess whether the percentage of predicted targets of a miRNA was significantly enriched in the Ago2-IP

Table 1 The Taqman Assay Catalog Number of miRNAs for Quantitative RT-PCR Validation

\begin{tabular}{|c|c|c|c|}
\hline No. & miRNA & TaqMan miRNA assay catalog number & Sequence \\
\hline 1 & $\operatorname{miR}-7-18763$ & 241023_mat & $5^{\prime}-\mathrm{AUCCCGGACGAGCCCCCA-3^{ \prime }}$ \\
\hline 2 & $\operatorname{miR}-9-5 p$ & 000583 & 5'-UCUUUGGUUAUCUAGCUGUAUGA-3' \\
\hline 4 & $\operatorname{miR}-24-3 p$ & 000402 & $5^{\prime}$-UGGCUCAGUUCAGCAGGAACAG-3' \\
\hline 5 & $\operatorname{miR}-27 a-3 p$ & 008196_mat & $5^{\prime}$-UUCACAGUGGCUAAGUUCCG- $3^{\prime}$ \\
\hline 6 & $\operatorname{miR}-28-5 p$ & 000411 & $5^{\prime}-$ AAGGAGCUCACAGUCUAUUGAG - $3^{\prime}$ \\
\hline 9 & $\operatorname{miR}-92 b-3 p$ & 242469_mat & $5^{\prime}$-UAUUGCACUCGUCCCGGCCU-3' \\
\hline 10 & $\operatorname{miR}-148 a-3 p$ & 000470 & $5^{\prime}$-UCAGUGCACUACAGAACUUUGU- $3^{\prime}$ \\
\hline 11 & $\operatorname{miR}-150-5 p$ & 000473 & $5^{\prime}$-UCUCCCAACCCUUGUACCAGUG-3' \\
\hline 12 & $\operatorname{miR}-190 a-5 p$ & 471572_mat & $5^{\prime}$-UGAUAUGUUUGAUAUAUUAGGUUG-3' \\
\hline 13 & $\operatorname{miR}-196 a-5 p$ & 241070_mat & $5^{\prime}$-UAGGUAGUUUCAUGUUGUUGGG-3' \\
\hline 18 & miR-363-3p & 001355 & $5^{\prime}-$ AAUUGCACGGUAUCCAUCUGU- $3^{\prime}$ \\
\hline 19 & $\operatorname{miR}-378 a-3 p$ & 001314 & $5^{\prime}-$ ACUGGACUUGGAGUCAGAAGGC $-3^{\prime}$ \\
\hline 20 & $\operatorname{miR}-615-3 p$ & 001588 & 5'-UCCGAGCCUGGGUCUCCCUCU-3' \\
\hline 21 & let-7b-5p & 000378 & 5'-UGAGGUAGUAGGUUGUGUGGUU-3' \\
\hline 22 & let-7f-2-3p & Custom assay & $5^{\prime}-$ CUAUACAGUCUACUGUCUUUCU-3' \\
\hline 23 & RNU44 (housekeeping gene) & 001094 & $\begin{array}{l}5^{\prime} \text { - CCTGGATGATGATAGCAAATGCTG- } \\
\text { ACTGAACATGAAGGTCTTAATTAGC- } \\
\text { TCTAACTGACT- } 3^{\prime}\end{array}$ \\
\hline
\end{tabular}


fraction as compared to the percentage in the list of genes expressed in HL cell lines.

\section{Functional Annotation Analysis}

DAVID bioinformatics Resources version 6.7 (https://david. ncifcrf.gov, last accessed January 10, 2017) ${ }^{32}$ was used to functionally annotate genes based on Gene Ontology category of biological process of GOTERM_BP_FAT.

\section{GFP Competition Assay}

Lentiviral miRZIP constructs to inhibit miR-23a/b-3p, miR24-3p, and miR-27a/b-3p and a nontargeting control (SCR) were purchased from System Biosciences (Palo Alto, CA). Lentiviral particles were produced in HEK-293T cells by calcium phosphate precipitation transfection. HL cells were infected with miRZIP lentivirus aiming at an infection percentage of $10 \%$ to $30 \%$. The cells were cultured for 22 days after infection. The percentage of green fluorescent protein $(\mathrm{GFP})^{+}$cells was monitored triweekly by fluorescenceactivated cell sorting (BD Biosciences, San Jose, CA). The percentage of GFP-positive cells at day 4 was set to $100 \%$. All GFP competition assays were performed three times.

\section{Apoptosis Assay}

The percentages of apoptotic cells were determined in L1236 and L428 cells harvested at day 5 and day 8 after transfection with the lentiviral miR-24-3p inhibitor (miRZIP-24-3p) and negative control miRZIP-SCR cells aiming at an infection percentage of $>95 \%$. Cells were washed twice with cold phosphate-buffered saline and resuspended at a concentration of $1 \times 10^{6}$ cells $/ \mathrm{mL}$ in $100 \mu \mathrm{L}$ calcium buffer $(2.6 \mu \mathrm{g} / \mathrm{mL}$ HEPES, $8.18 \mu \mathrm{g} / \mathrm{mL} \mathrm{NaCl}$, and $0.28 \mu \mathrm{g} / \mathrm{mL} \quad \mathrm{CaCl}_{2}$ ). After staining with Annexin V-APC (BD Biosciences), cells were analyzed by fluorescence-activated cell sorting (BD Biosciences).

\section{Western Blot}

Cells were lysed in cell lysis buffer (9803; Cell Signaling Technology, Danvers, MA) supplemented with phenylmethylsulfonyl fluoride protease inhibitor. Lysates were kept on ice for 30 minutes and centrifuged at $20,817 \times g$ for 15 minutes at $4{ }^{\circ} \mathrm{C}$ and supernatant was collected. Protein concentration was measured using the BCA Protein Assay Kit (Thermo Fisher Scientific Inc.) following the manufacturer's instructions. Protein $(20 \mu \mathrm{g})$ was separated on a polyacrylamide gel and transferred to a nitrocellulose membrane. The membrane was incubated overnight at $4^{\circ} \mathrm{C}$ with primary antibodies diluted in 5\% milk in Tris-buffered saline with Tween-20 with anti-BCL2L11 (1000× dilution; C34C5; rabbit monoclonal antibody; Cell Signaling Technology), anti-cyclin-dependent kinase inhibitor 1B [CDKN1B; 100× dilution; P27 (C-19) sc-528; rabbit polyclonal antibody;
Santa Cruz Biotechnology, Dallas, TX], anti-MYC (5000× diluted; 1472-1; rabbit monoclonal antibody; Epitomics, Burlingame, CA), anti-sphingosine-1-phosphate receptor 1 (S1PR1; 1000× diluted; ab125074; rabbit monoclonal antibody; Abcam, Cambridge, UK), anti-CARD10 (500× diluted; SAB2702056; rabbit polyclonal antibody; Sigma, Dorset, UK), and anti-Ago2 (1000 $\times$ diluted; 2E12-1C9; Abnova, Taipei City, Taiwan). A secondary incubation step was performed with goat anti-rabbit or rabbit anti-mouse antibodies (1000× diluted; Dako, Glostrup Municipality, Denmark) conjugated with horseradish peroxidase. Chemoluminescene was detected with Chemi Doc MP scanner and proteins were visualized and quantified with Image Lab software version 4.0.1 (BioRad, Hercules, CA).

\section{Immunohistochemistry}

Generation of the HL tissue microarrays has been described previously. ${ }^{33}$ A total of 51 primary diagnostic paraffinembedded cHL tissue samples were stained with thymus and activation regulated chemokine (TARC; $50 \times$ diluted; AF364; polyclonal goat IgG antibody; R\&D Systems, Abingdon, UK), anti-CDKN1B [100× dilution; P27 (C-19) sc-528; rabbit polyclonal antibody; Santa Cruz Biotechnology], and anti-MYC $(50 \times$ diluted; 1472-1; rabbit monoclonal antibody; Epitomics). Antigen retrieval was performed in $0.1 \mathrm{~mol} / \mathrm{L}$ citrate $(\mathrm{pH}$ 6.0) for TARC and Tris EDTA buffer ( $\mathrm{pH}$ 8.0) in a pressure cooker for 15 minutes. Tissue sections were incubated with primary antibodies for 1 hour at room temperature. The binding was visualized after with 3,3'-diaminobenzidine after second and third antibody incubation steps. Staining with TARC on subsequent tissue sections was used to identify HRS tumor cells. Only cores with $\geq 10$ tumor cells were included in the analysis of CDKN1B/P27 $7^{\text {kip } 1}$ and MYC protein expression patterns in HL.

\section{Statistical Analysis}

Differential expression of miRNAs between HL cell lines and GC-B cells by quantitative RT-PCR (RT-qPCR) was established using the nonparametric $U$-test (GraphPad Software Inc., San Diego, CA). For the GFP competition assay, the decrease in percentages of GFP-positive cells in the HL cell lines infected by a miRNA inhibitor (miR$23 \mathrm{a} / \mathrm{b}-3 \mathrm{p}$, miR-24-3p, or miR-27a/b-3p) over time was compared with that of miRZIP-SCR using a mixed model with time and the interaction of time and miRNA inhibitor type as fixed effect and measurement repeat within miRNA inhibitor type as random effect in SPSS (22.0.0.0 version; IBM, Armonk, New York, NY). In case of a nonlinear relation between time and decrease of GFP-positive cell percentages (determined by visual inspection of the graph), quadratic terms for time itself and for time interacting with miRNA inhibitor type were added to the model. No (fixed and random) intercept was included in the model, 
as the percentages at time 0 were set to $100 \%$ and percentages $-100 \%$ were analyzed. The interaction term is the parameter of interest, as this identifies whether the decrease over time differs between the miRNA and SCR. $P<0.05$ was considered statistically significant.

\section{Results}

miRNA Profiling by Small RNA Sequencing

An overview of the total number of reads and percentages of mapped reads is given in Supplemental Table S1. The miRNA expression patterns were determined in four $\mathrm{cHL}$ cell lines (L1236, L428, L540, and KM-H2), and GC-B cells sorted from three independent tonsils. The top 10 most abundantly expressed miRNAs in HL cells and GC-B cells showed an overlap of six miRNAs (Figure 1). In HL, the top 10 miRNAs were known, whereas in GC-B cells nine known and one novel miRNA were observed. The expression level of the top 10 most abundant miRNAs accounted for $61 \%$ of all reads in $\mathrm{HL}$ and for $70 \%$ in GC-B cells.

A total of 84 miRNAs were significantly differentially expressed between HL cells and GC-B cells, including 55 up-regulated (54 known and 1 novel) and 29 downregulated (26 known and 3 novel) miRNAs (Figure 2A). None of the 10 most abundant miRNAs in HL were significantly differentially expressed between HL and GC-B cells.

A total of 15 up-regulated and seven down-regulated miRNAs were selected for validation by RT-qPCR. The expression levels of 3 of 15 up-regulated miRNAs were lower than the detection limit. For 11 of 15 miRNAs significantly increased levels were observed in $\mathrm{HL}$ cell lines compared to GC-B cells (ie, miR-9-5p, miR-23a-3p, miR-24-3p, miR-27a-3p, miR-92b-3p, miR-196a-5p, miR301b-3p, miR-320a-3p, miR-345-5p, miR-378a-3p, and miR-615-3p) (Figure 2B). Unexpectedly, a significant decrease in let-7b-5p levels was observed in HL, a pattern opposite to that observed with small RNA sequencing (Figure 2B). For four of seven down-regulated miRNAs a significantly decreased expression level was confirmed in HL cell lines compared to GC-B cells (ie, miR-28-5p, miR148a-3p, miR-150-5p, and miR-363-5p) (Figure 2C). For miR-28-3p, miR-30a-5p, and miR-7-18763, the downregulation could not be validated. These results showed that the differential expression pattern could be confirmed for most of the miRNAs.

\section{miR-24-3p and miR-27-3p Act as Oncogenes in $\mathrm{HL}$}

miR-23, miR-24, and miR-27 are transcribed from two primary miRNA transcripts (ie, C9orf3, located at chromosome 9, and LOC284453, located at chromosome 19). C9orf3 is the primary (pri-)miRNA transcript of miR-23b, miR-27b, and miR-24-1 and LOC284454 is the pri-miRNA transcript of miR-24-2, miR-27a, and miR-23a. miR-27b-3p was in the top 10 most abundantly expressed miRNAs; miR-23a-3p, miR-24-3p, and miR-27a-3p were differentially expressed. To study the functional relevance of these miRNAs on HL cell growth, we inhibited miR-23a/b-3p, miR-24-3p, and miR-27a/b-3p using specific miRNA inhibitors (miRZIP) in four HL cell lines. We observed
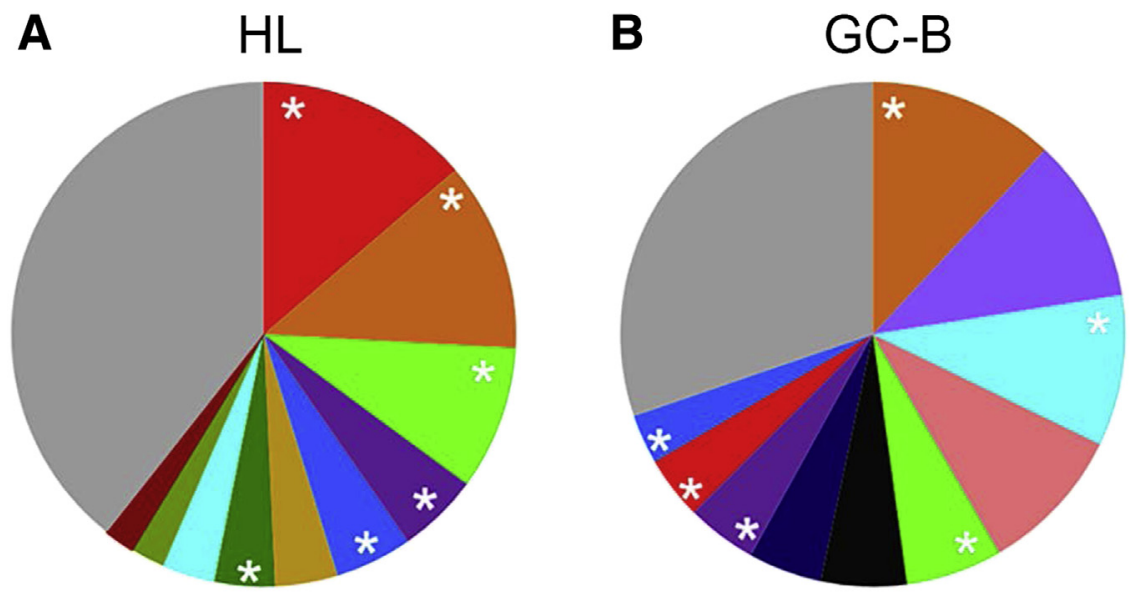

Figure 1 The top 10 most abundant miRNAs in Hodgkin lymphoma (HL) and germinal center (GC)B cells. A: The top 10 most abundant miRNAs in $\mathrm{HL}$ cell lines; these most abundant miRNAs account for $61 \%$ of all reads. B: The top 10 most abundant miRNAs in GC-B cells, accounting for $70 \%$ of all reads. Asterisks indicate miRNAs present in the top 10 of both $\mathrm{HL}$ cell lines and GC-B cells.
* miR-21-5p
miR-155-5p
miR-191-5p
Let-7a-5p
miR-92a-3p
* miR-142-5p
* 2 Let-7f-5p
miR-28-3p
miR-7-18763
- miR-148a-3p
- miR-486-5p
Others 

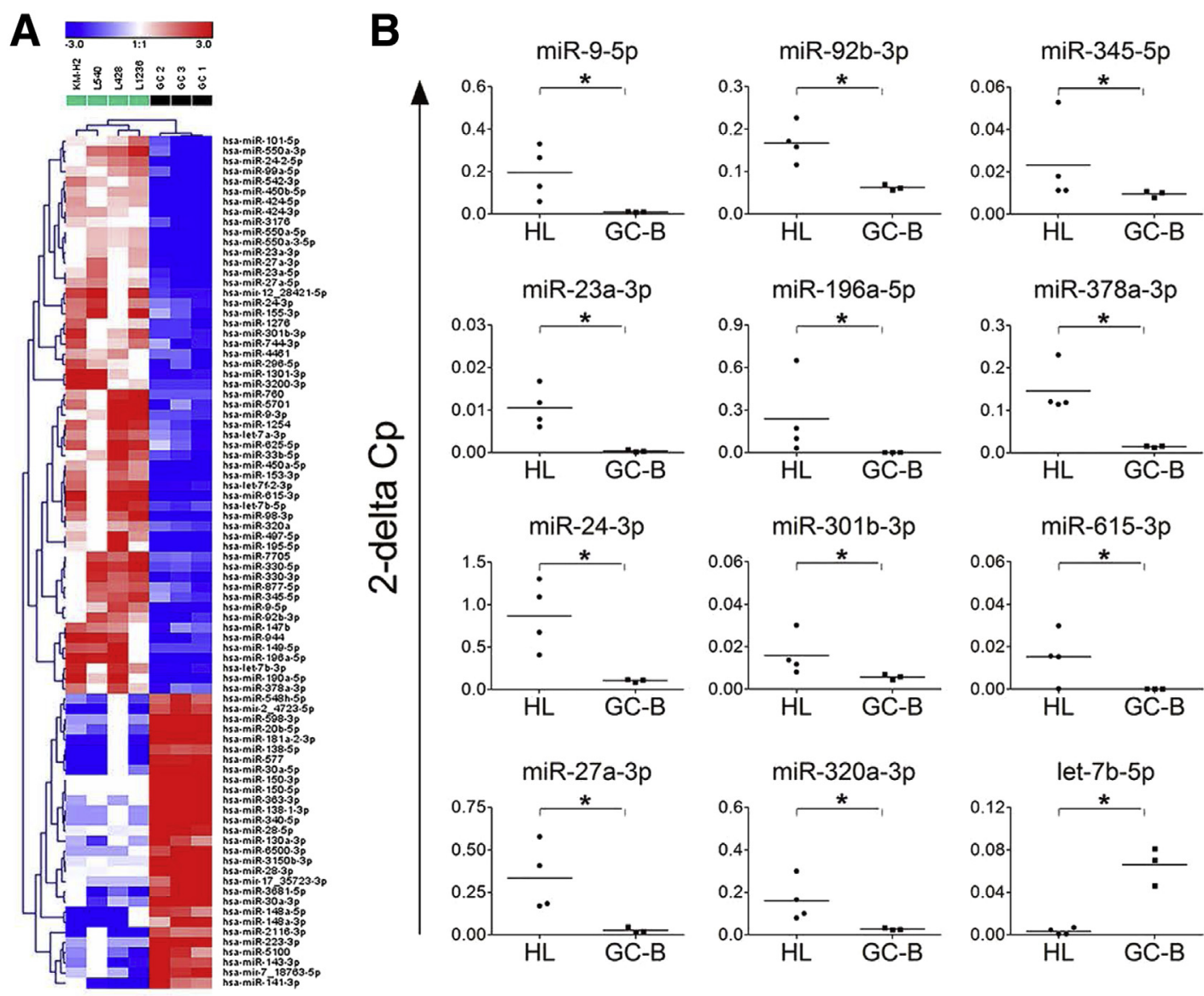

C

miR-7-18763

$\operatorname{miR}-148 a-3 p$
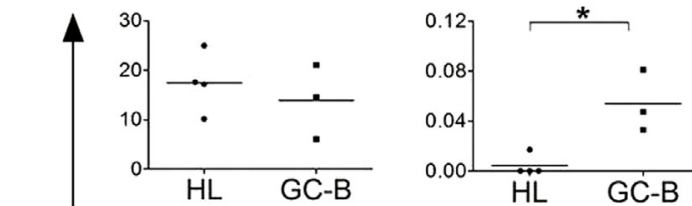

miR-28-5p

miR-150-5p

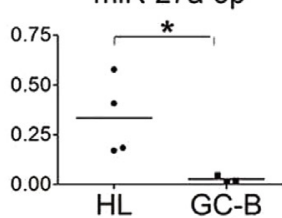

miR-320a-3p
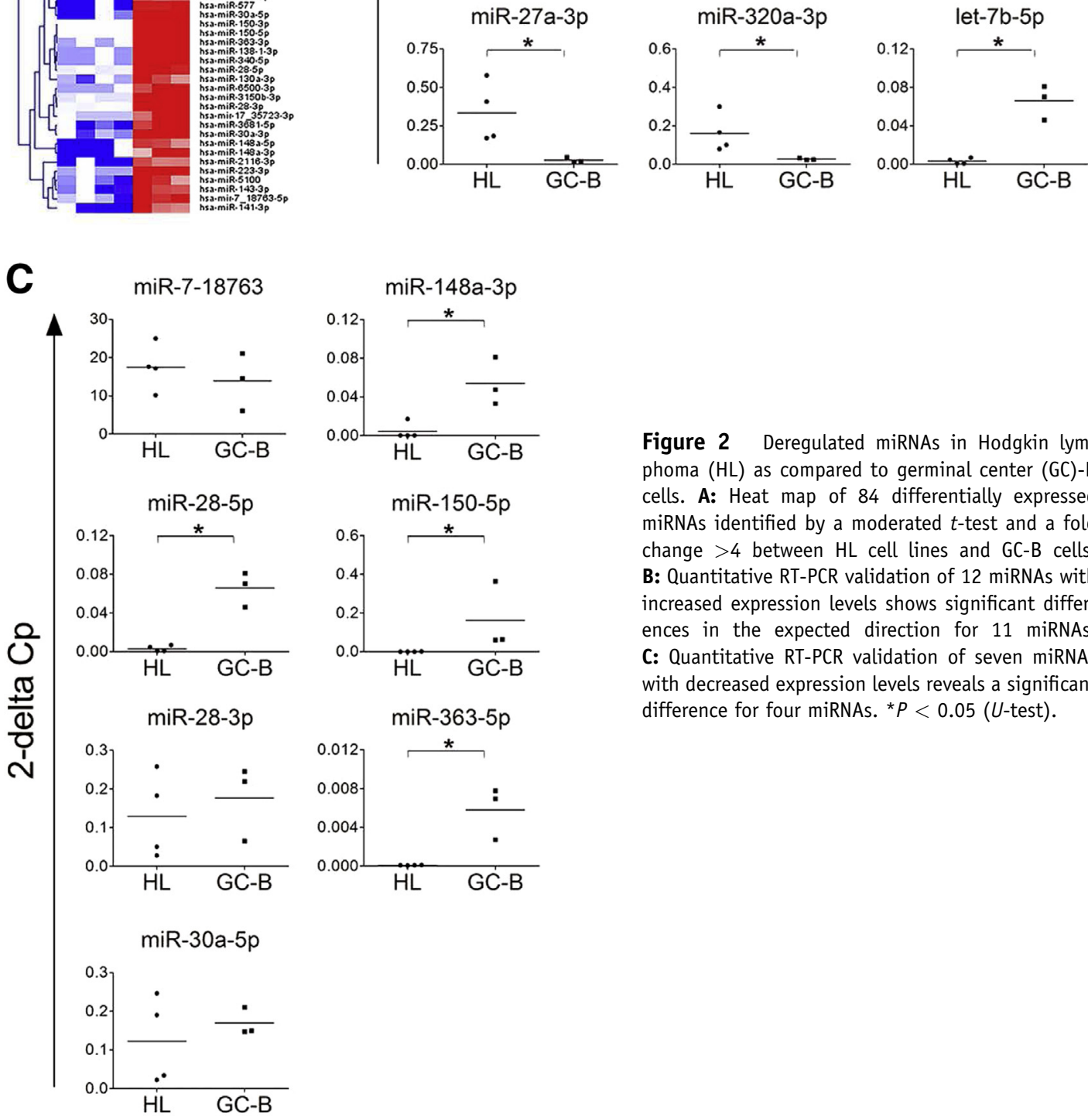

phoma (HL) as compared to germinal center (GC)-B cells. A: Heat map of 84 differentially expressed miRNAs identified by a moderated $t$-test and a fold change $>4$ between $\mathrm{HL}$ cell lines and GC-B cells. B: Quantitative RT-PCR validation of 12 miRNAs with increased expression levels shows significant differences in the expected direction for 11 miRNAs. C: Quantitative RT-PCR validation of seven miRNAs with decreased expression levels reveals a significant difference for four miRNAs. ${ }^{*} P<0.05$ (U-test). 
a significant decrease over time in the percentage of GFP-positive cells for miRZIP-24-3p compared to the control in L1236, L428, and KM-H2 (Figure 3A). A significant decrease in GFP-positive cells was seen for miRZIP-27a-3p in L1236 and L540 as well as for miRZIP27b-3p in L1236 (Supplemental Figure S1). For miRZIP23a-3p we found either no effect or a significant increase (in L540) possibly because of a continued decrease of the percentage of $\mathrm{GFP}^{+}$cells in miRZIP-SCR infected cells (Supplemental Figure S1).

To study the cause of the decrease in the percentages of GFP-positive cells, we analyzed cell cycle distribution and the presence of apoptotic cells in L1236 and L428 at day 5 and day 8 on miR-24-3p inhibition. We found no effect on the distribution of the cell cycle phases (data not shown). The percentage of apoptotic cells based on annexin $\mathrm{V}$ staining was significantly increased in both L1236 and L428 on inhibition of miR-24-3p (Figure 3B). In line with a stronger decrease in cell growth in L1236, the increase of apoptotic cells was also the highest in L1236. Thus, inhibition of miR-24-3p leads to an increase of apoptotic cells in HL, providing an explanation for the decrease in $\mathrm{GFP}^{+}$cells in the growth competition assay.

\section{Identification of miRNA Target Genes by Ago2- RIP-Chromatin IP}

IP with anti-Ago2 was performed to pull down mRNA transcripts of miRNA target genes in HL cell lines. The efficiency of the IP procedure was validated by Western blot and RT-qPCR. Ago2 protein was detected in the Ago2-IP and the total cell lysate fractions but not in flow through (Supplemental Figure S2A). In the control IgG-IP samples, Ago2 protein was present in the total and flow through fractions but not in the IP. Using RT-qPCR, we observed a strong enrichment of two randomly selected highly expressed miRNAs in the Ago2-IP but not in the IgG-IP fractions (Supplemental Figure S2B). Using gene set enrichment analysis, we identified significant enrichment of multiple miRNA target gene sets in all four HL cell lines. The miRNA gene sets of top 10 miRNAs in HL were all significantly enriched in the Ago2-IP (Supplemental Table S2). Of the 17 in HL up-regulated miRNAs with the highest read frequencies (at least 200 read counts per million on average), 12 showed significant enrichment of their miRNA target gene sets. For the remaining miRNAs, no target gene sets were available for three, whereas no significant enrichment was observed for two (Supplemental Table S2). All together, these data confirmed the efficiency of the Ago2-IP enrichment procedure.

To define the set of genes regulated by miRNAs in HL, we determined the Ago2-IP over total signal intensity ratios of all probes. The number of probes enriched in the Ago2-IP fraction (IP/T >2) was 2080 in KM-H2, 3230 in L1236, 2107 in L428, and 2171 in L540 (Figure 4A). Using a threshold of having an IP/T $>2$ in at least three of four cell lines, we identified 1142 unique protein-coding genes (represented by 1434 probes) that together represent the HL miRNA-targetome (Figure 4A and Supplemental Table S3).

We next determined whether the putative target genes of the 11 validated up-regulated miRNAs were enriched in the HL miRNA targetome. For eight miRNAs, we observed significant enrichment of target genes in the Ago2-IP fractions (Figure 4C and Table 2). For the remaining three, few of the predicted targets were expressed in HL. As negative control, we also analyzed enrichment of five miRNAs with low or no expression in HL (ie, miR-342-5p, miR-4488-5p, miR-3150b-3p, miR-150-3p, and miR-6500-3p). No enrichment was seen for four of these miRNAs (Figure 4B).

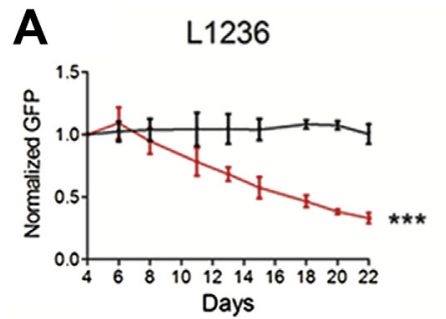

B
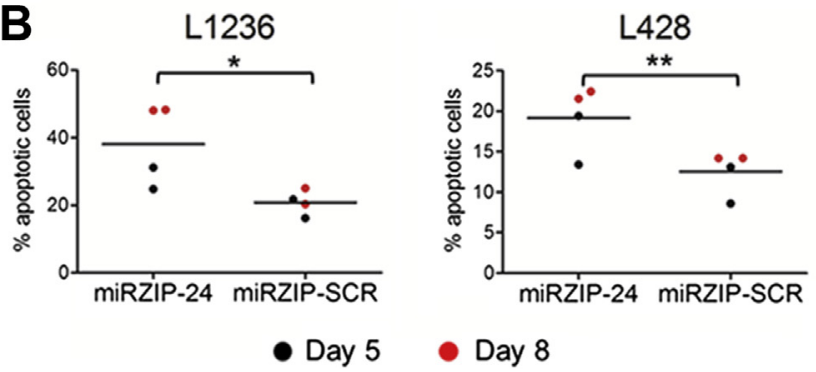

L428

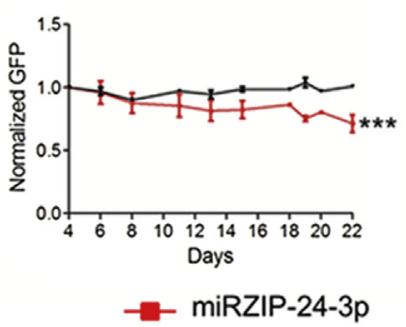

Figure 3 The effect of miR-24-3p inhibition on cell growth and apoptosis. A: Green fluorescent protein (GFP) competition assay of miR-24-3p inhibitor (miRZIP-24-3p) and control miRZIP-SCR-infected Hodgkin lymphoma (HL) cell lines L1236, L428, L540, and KM-H2. MiRZIP-24-3p was stably transfected in cells using a viral vector, which coexpresses GFP. The GFP percentage was measured triweekly for 22 days, and the percentage at the first day of measurement (day 4) was set to 1 . Significant differences were calculated using a mixed model analysis. B: The percentage of apoptotic cells on inhibition of miR24-3p in L1236 and L428 was assessed by determining the percentage of annexin $\mathrm{V}$-positive cells at day 5 and day 8 after lentiviral infection in duplicate. Data are expressed as means \pm SD (A). $n=3(\mathbf{A}) .{ }^{*} P<0.05,{ }^{* *} P<0.01$, and ${ }^{* * *} P<0.001$ versus miRZIP-SCR (paired $t$-test). 

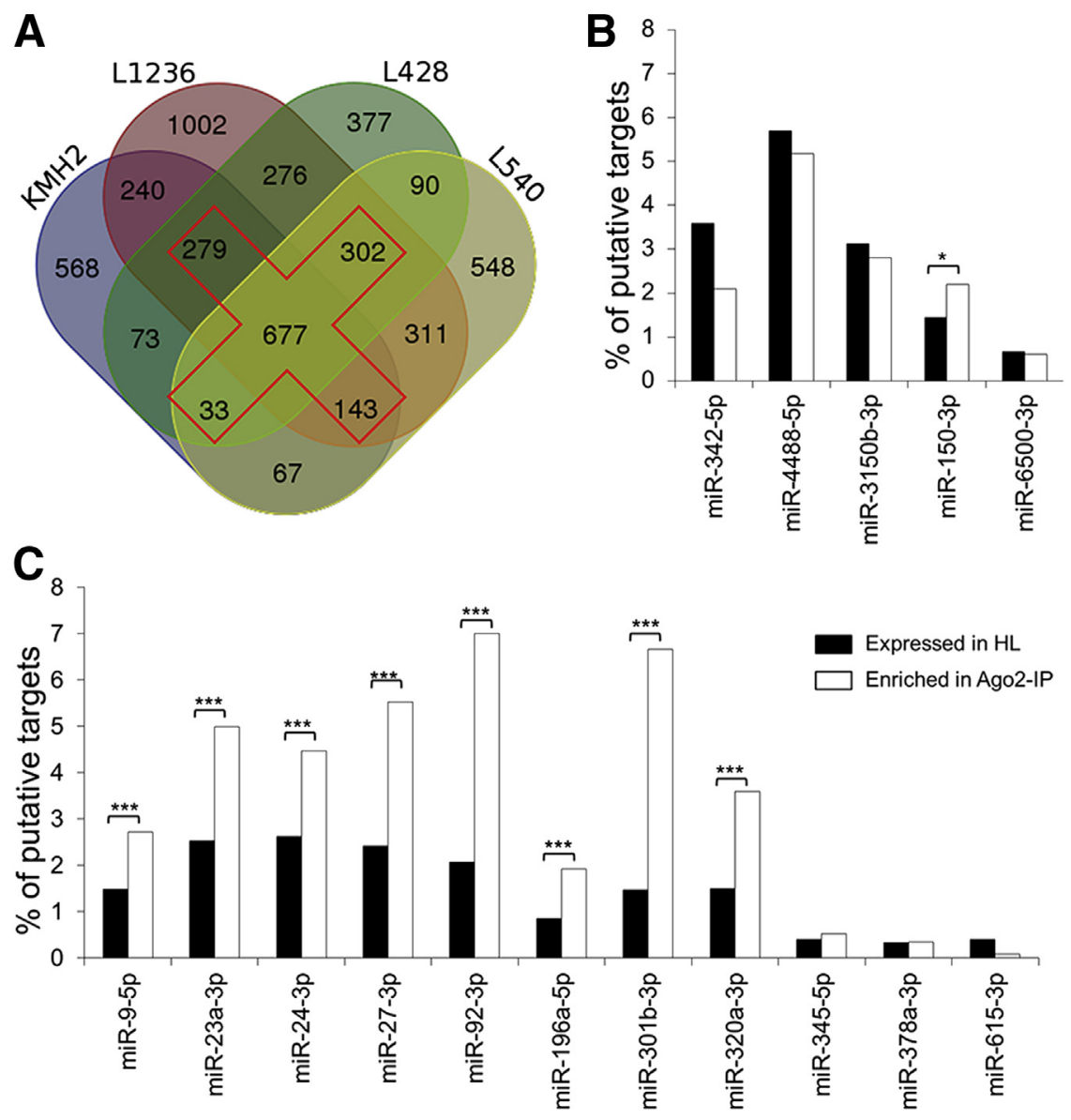

For miR-150-3p, we observed a moderate but significant increase of predicted target gene set, although the expression of this miRNA is low in HL (average less than seven reads per million). This is probably caused by the high overlap of putative miR-150-3p target genes with targets of one or more of the top 10 most abundant miRNAs in HL (12/25 genes).

\section{CDKN1B/P2 $7^{\text {kip1 }}$ and MYC Are Targets of miR-24-3p}

To identify target genes that might be relevant for the observed miR-24-3p phenotype, we first determined how many predicted and/or validated miR-24-3p target genes were Ago2-IP enriched in the HL cell lines. This revealed a total of 52 putative miR-24-3p target genes among the 1142 consistently Ago2-IP enriched genes (Supplemental Table S4). Functional annotation analysis revealed gene ontology related to cell growth and apoptosis for 15 of these targets (Table 3). Six of the 15 putative miR-24-3p targets (ie, CDKN1B, ${ }^{34,35}$ SIPR $1,{ }^{36}$ CARD10, ${ }^{37}$ BCL2L11, ${ }^{38}$ MYC, ${ }^{39}$ and INSIG1) ${ }^{40}$ were validated previously. Based on average fold changes in the Ago2-IP/T fractions, the top five genes were selected for further analysis by Western blot. CDKN1B/P2 $7^{\text {kip } 1}$ and S1PR1 contained one conserved 8-mer binding site in the 3'untranslated region, BCL2 like 11 (BCL2L11) contained two
Figure 4 Identification of target genes of each miRNA family. A: Ago2-IP-enriched mRNA probes per cell line (fold change of IP/total $>2$ ) and the 1434 probes (1142 genes) that are IP-enriched in at least three of the four Hodgkin lymphoma (HL) cell lines (red cross). B: Comparison of the percentage of Targetscan-predicted target genes among the expressed and Ago2-IP-enriched of five miRNAs with low expression levels in HL. C: Comparison of the percentage of Targetscanpredicted target genes among the expressed and Ago2-IP enriched of 11 differentially expressed and validated miRNAs. ${ }^{*} P<0.05,{ }^{* *} P<0.001$ ( $\chi^{2}$ test). conserved 8-mer sites, CARD10 contained two poorly conserved 7-mer-m8 binding sites, and MYC contained one poorly conserved 7-mer-A binding site. The endogenous protein level of CDKN1B/P2 $7^{\text {kip } 1}$ was lower in KM-H2 compared to the three other cell lines (Supplemental Figure S3A). MYC levels were low in L1236 (Supplemental Figure S3B) and higher in the other cell lines. The levels of BCL2L11 were the highest in L1236 and low in KM-H2 and L540 (Supplemental Figure S3C). The S1PR1 protein levels were highest in L428 and slightly lower in the other cell lines (Supplemental Figure S3D). CARD10 protein levels were lower than the detection limit in all four HL cell lines (data not shown).

To establish a possible effect of miR-24-3p on the expression of the four proteins expressed in HL, we analyzed their levels on inhibition of miR-24-3p in L1236 and L428. Inhibition of miR-24-3p had no effects on BCL2L11 and S1PR1 protein levels in either L1236 or L428 (Supplemental Figure S3, E and F). CDKN1B/P27 $7^{\text {kip1 }}$ and MYC protein levels were consistently increased in miRZIP-24-3p-infected L1236 cells compared to control miRZIP-SCR infected cells. In contrast, no changes in protein levels were observed in L428 cells (Figure 5A). To further explore the relevance of CDKN1B/P27 $7^{\text {kip1 }}$ and MYC as targets of miR-24-3p in HL, we analyzed two additional HL cell lines (ie, HDLM2 and 
Table 2 Ago2-Immunoprecipitation Data Analysis of miRNAs Up-Regulated in Hodgkin Lymphoma

\begin{tabular}{lccc}
\hline & \multirow{2}{*}{$\begin{array}{c}\text { Quantitative } \\
\text { RT-PCR }\end{array}$} & \multicolumn{2}{c}{ Ago2-IP } \\
\cline { 3 - 4 } miRNAs & $\begin{array}{c}\text { validation } \\
\text { miRNA gene }\end{array}$ & $\begin{array}{c}\text { miRNA targets } \\
\text { sets enriched }\end{array}$ & enriched \\
\hline hsa-miR-9-5p & Yes & Yes & Yes \\
hsa-miR-23a-3p & Yes & Yes & Yes \\
hsa-miR-24-3p & Yes & Yes & Yes \\
hsa-miR-27a-3p & Yes & Yes & Yes \\
hsa-miR-92b-3p & Yes & Yes & Yes \\
hsa-miR-196a-5p & Yes & Yes & Yes \\
hsa-miR-301b-3p & Yes & Yes & Yes \\
hsa-miR-320a & Yes & No & Yes \\
hsa-miR-345-5p & Yes & No & No \\
hsa-miR-378a-3p & Yes & No & No \\
hsa-miR-615-3p & Yes & NA & No \\
hsa-let-7b-5p & No & Yes & Yes \\
\hline
\end{tabular}

NA, not applicable.

SUPHD1). Inhibition of miR-24-3p induced a reduction in cell growth similar to the other HL cell lines (Figure 5C). Moreover, an increase in $\mathrm{CDKN} 1 \mathrm{~B} / \mathrm{P} 27^{\mathrm{kip} 1}$ protein levels on inhibition of miR-24-3p was observed in both cell lines, whereas an increase in MYC protein levels was observed only in HDLM2 (Figure 5B).
To evaluate protein expression in HRS cells, we analyzed their expression in HL tissue samples. CDKN1B/P2 $7^{\text {kip1 }}$ $(46 / 46=100 \%)$ and MYC $(42 / 46=91 \%)$ were expressed in most HL cases (Figure 5D and Supplemental Table S3). The percentages of $\mathrm{CDKN} 1 \mathrm{~B} / \mathrm{P} 27^{\mathrm{kip} 1}$ positive tumor cells varied from $5 \%$ to $100 \%$ and of MYC varied from $0 \%$ to $90 \%$. Staining in $>50 \%$ of the tumor cells was observed in 26 of 46 for CDKN1B/P27 $7^{\text {kip1 }}$ and in 22 of 46 for MYC. No obvious correlation was observed between CDKN1B/P2 $7^{\text {kip } 1}$ and MYC protein expression in HRS cells of HL cases.

\section{Discussion}

In this study, we found a total of 84 significant differentially expressed miRNAs in HL cell lines compared to GC-B cells. Three of these miRNAs (ie, miR-23a-3p, miR24-3p, and miR-27a-3p) were transcribed from a single primary miRNA transcript. miR-24-3p inhibition impaired the cell growth in five of six cell lines, by increasing the number of apoptotic cells. Moreover, 52 of 1142 Ago2-IP enriched genes were predicted miR-24-3p targets. $\mathrm{CDKN} 1 \mathrm{~B} / \mathrm{P} 27^{\mathrm{kip} 1}$ and MYC protein levels were regulated by miR-24-3p in HL cell lines and both proteins were expressed in a variable percentage of the tumor cells in primary HL tissue samples.

Table 3 Fifteen Ago2-IP-Enriched Predicted miR-24-3p Target Genes Related to Cell Growth

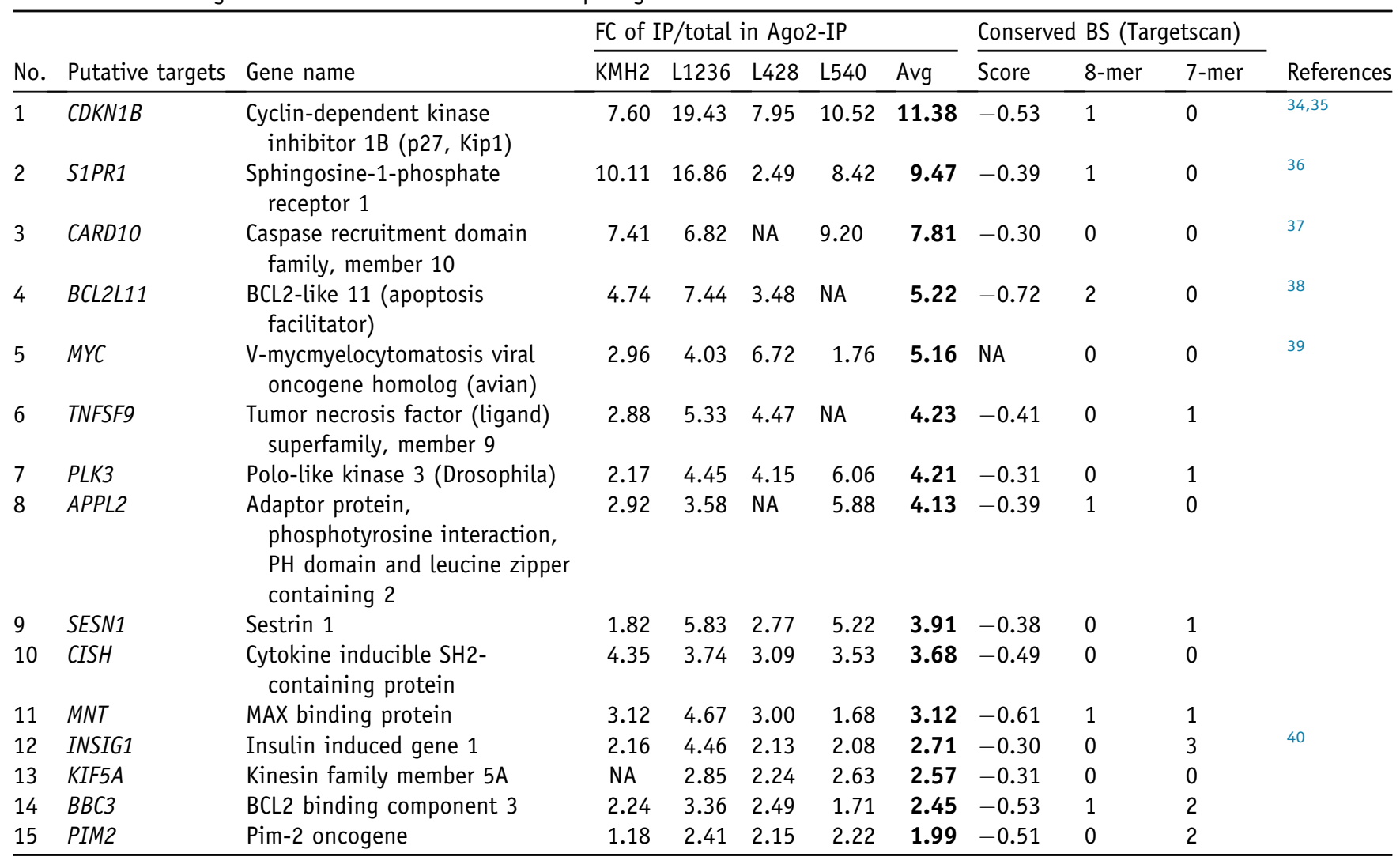

Score: Cumulative weighted context ++ score in Targetscan. Putative targets were sorted based on average FC (avg) in bold. References are given for all previously validated target genes of miR-24-3p.

Avg, average; BS, binding site; FC, fold change; IP, immunoprecipitation; NA, not applicable. 

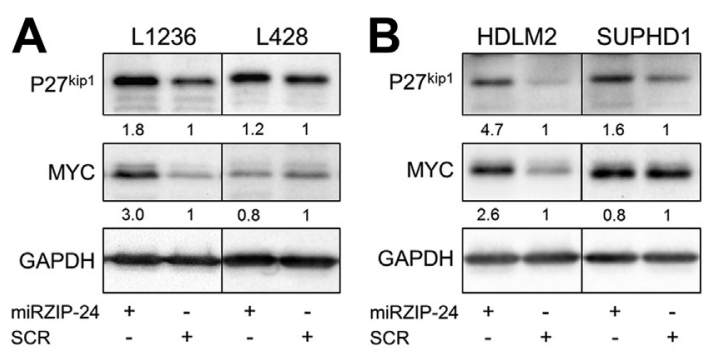

D

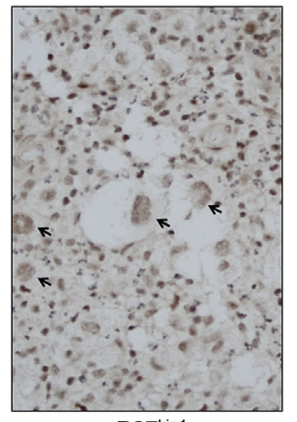

$\mathrm{P} 27^{\text {kip } 1}$

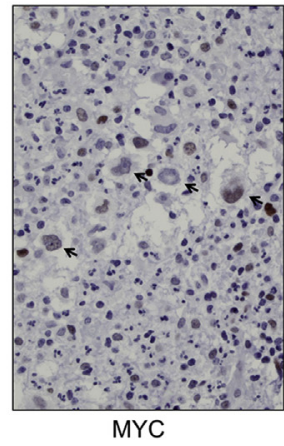

HDLM2

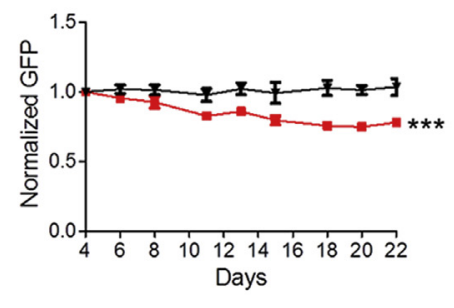

SUPHD1

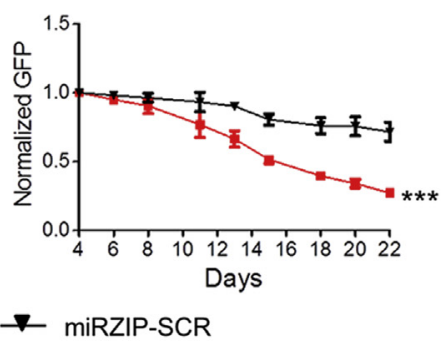

Figure $5 \quad$ CDKN1B/P27 $7^{\mathrm{kip} 1}$ and MYC are target genes of miR-24-3p in Hodgkin lymphoma (HL). A: Effect of miR-24-3p inhibition on the protein levels of CDKN1B/P27 $7^{\text {kip1 }}$ and MYC in L1236 and L428. Cells were harvested at day 5 after infection with miRZIP-24$3 p$ and miRZIP-SCR in one of two independent experiments. B: miR-24-3p inhibition effects on the protein levels of CDKN1B/P2 $7^{\mathrm{kip} 1}$ and MYC in HDLM2 and SUPHD1. Cells were harvested at day 5 for HDLM2 and day 10 for SUPHD1 after infection in one experiment. Protein levels were normalized to glyceraldehyde-3-phosphate dehydrogenase (GAPDH). C: GFP competition assay of miRZIP-24-3p and miRZIP-SCR infection on HDLM2 and SUPHD1 HL cell lines. D: Representative HL case showing expression of CDKN1B/P27 $7^{\text {kip } 1}$ and MYC in HRS tumor cells (arrows). Data are expressed as means \pm SD $(\mathbf{C}) . n=3(\mathbf{C}) .{ }^{* *} P<0.001$ versus miRZIP-SCR (mixed model analysis). Original magnification, $\times 400$ (D).
Validation of the small RNA sequencing data by RTqPCR revealed consistent results for most of them. Some of the miRNAs showed a different pattern by RT-qPCR. For miR-30a-5p, this might be caused by high expression of other miRNAs of the same seed family $(\mathrm{miR}-30 \mathrm{a} / \mathrm{b} / \mathrm{c} / \mathrm{d} / \mathrm{e}-5 \mathrm{p})$. The mature miRNA sequences of miR-30d-5p and miR-30e-5p differ by only one nucleotide from miR-30a-5p. The expression of miR-30d-5p and miR-30e-5p is more abundant in $\mathrm{HL}$ and these miRNAs have similar expression levels in GC-B cells (data not shown). So, this might explain the difference between small RNA sequencing and RT-qPCR results. For let-7-5p, miR-28-3p, and the novel miRNA miR$7-18763$, we could not explain the differences between the two techniques. For let-7-5p, this is unexpected as all eight let-7-5p family members show the same pattern with higher read counts in HL compared to GC-B cells.

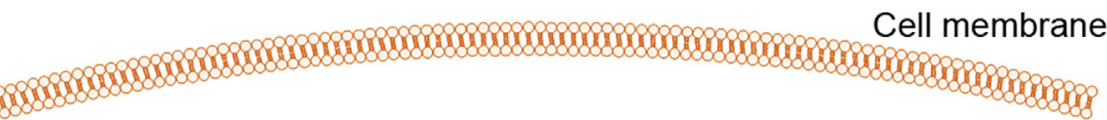

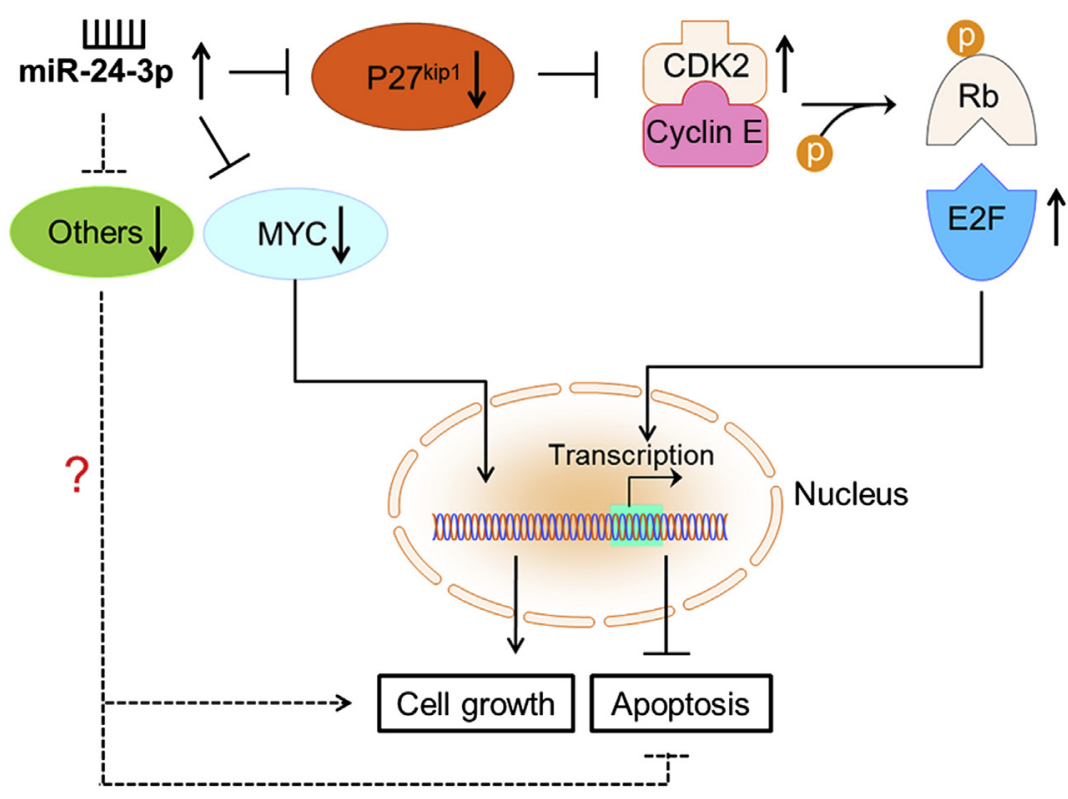

Figure 6 Model of the oncogenic action of miR-24-3p in Hodgkin lymphoma (HL). High miR24-3p levels result in reduced CDKN1B/P27 ${ }^{\text {kip1 }}$ levels. Loss of this negative regulator leads to activation of CDK2/Cyclin E, which leads to phosphorylation of the retinoblastoma protein $(\mathrm{Rb})$ and release of the E2F transcription factor. Downstream E2F promote proliferation and inhibit apoptosis. High miR-24-3p levels also lead to reduced MYC protein levels, which might contribute to decreased sensitivity to apoptosis. Thus, miR-24-3p plays a role in growth and survival of $\mathrm{HL}$ cells by regulating the protein levels of CDKN1B/P27 $7^{\text {kip } 1}$ and MYC. 
Based on the reduced growth of HL cells on inhibition of miR-24-3p, we concluded that this miRNA might have an oncogenic role in HL. Several other studies also revealed an oncogenic role for miR-24-3p in other types of cancers, including gastric cancer, ${ }^{38}$ pancreatic carcinoma, ${ }^{41}$ and tongue squamous cell carcinoma. ${ }^{42}$ On the other hand, tumor suppressor activity has also been reported for miR-24-3p in breast cancer, cervical cancer, ${ }^{43}$ and gastric cancer. ${ }^{44}$

Nie et $\mathrm{al}^{45}$ showed abundant expression of miR-24-3p in HL cell lines; however, in our study, the levels were more average (average rank, 84 of 453 miRNAs expressed). This difference might be caused by differences in experimental procedures. The previous study used cloning of miRNAs, followed by sequencing, and mapped their miRNAs to miRBASE version 9.1 (version 9.1 contains 4449 entries). ${ }^{45}$ We used small RNA sequencing and mapped our miRNAs to miRBASE version 21 (version 21 contains 28,645 entries).

Of the top five putative target genes of miR-24-3p based on Ago2-IP analysis, we found no protein expression for CARD10, whereas levels of BCL2L11 and S1PR1 did not change on miR-24-3p inhibition. For the other two top five targets, we observed an increase in protein level on inhibition of miR-24-3p. For CDKN1B/P2 $7^{\text {kip } 1}$, protein levels increased in three of four HL cell lines, and for MYC, protein levels increased in two of four cell lines. CDKN1B/P27 $7^{\mathrm{kip} 1}$ belongs to the Cip/Kip family of CDK inhibitor proteins. $\mathrm{CDKN} 1 \mathrm{~B} / \mathrm{P} 27^{\mathrm{kip} 1}$ prevents activation of the cyclin $\mathrm{E}-\mathrm{CDK} 2$ complex. By phosphorylating $\mathrm{Rb}$, this complex regulates the release of E2Fs, transcription factors with important functions in the control of cell cycle progression and apoptosis. ${ }^{46,47}$ This implicates that high miR-24-3p levels possibly promote cell growth and protect from apoptosis by inhibiting $\mathrm{CDKN} 1 \mathrm{~B} / \mathrm{P} 27^{\mathrm{kip} 1}$ in HL (Figure 6). MYC is a transcription factor that can both activate and repress its target genes. MYC target genes have been shown to play a role in cell cycle, apoptosis, and cellular transformation. ${ }^{48}$ On the one hand, overexpression of MYC has been associated with development of many types of cancers. ${ }^{49,50}$ In line with this, it was shown that knockdown of MYC increased apoptosis in L1236, L428, and L540 HL cell lines. ${ }^{51}$ On the other hand, MYC expression was required to induce apoptosis in some types of cells (eg, in fibroblasts). ${ }^{52}$ This induction of apoptosis in fibroblasts was shown to be p53 dependent. ${ }^{53}$ The two HL cell lines that showed an increase in MYC on miR-24-3p inhibition (L1236 and HDLM2) and one of the cell lines that did not show an increase in MYC on miR-24$3 p$ inhibition (L428) had a mutation in the p53 gene. ${ }^{54,55}$ Thus, in HL, the increase in apoptosis on miR-24-3p inhibition seems not to be related to the p53 mutational status. Others have shown that induction or sensitization that leads to apoptosis on high levels of MYC can also be p53 independent. ${ }^{56}$ MYC can sensitize cells to CD95/Fas-mediated apoptosis $^{57}$ and amplify the mitochondrial apoptotic pathway by inhibiting antiapoptotic members of the BCL2 family and activating proapoptotic BCL2 members. ${ }^{58,59}$
Thus, we speculate that both increased and decreased MYC levels might negatively affect HL cell growth.

Immunohistochemistal staining for $\mathrm{CDKN} 1 \mathrm{~B} / \mathrm{P} 27^{\mathrm{kip} 1}$ and MYC in primary HL tissues did not reveal a clear correlation between their expression levels. This implicated that miR24-3p was not the only factor regulating their expression levels. It might be that other miRNAs target one, but not the other gene, which might explain the lack of correlation between these two proteins. If such a miRNA is variably expressed in HL, then CDKN1B/P2 $7^{\text {kip } 1}$ and MYC repression will not only vary based on miR-24 expression. The expression of CDKN1B/P27 ${ }^{\text {kip } 1}$ and MYC might also differ because of changes in the presence of other regulators, such as specific transcription factors or different epigenetic marks.

In summary, we showed a specific miRNA expression profile in HL and characterized the HL miRNA targetome. Inhibition of the oncogenic miR-24-3p induced apoptosis, possibly via targeting CDKN1B/P27 $7^{\text {kip } 1}$ and MYC.

\section{Acknowledgments}

We thank Geert Mesander and Henk Moes for flow cytometry assistance and members from the Department of Otorhinolaryngology/Head and Neck Surgery (University Medical Center Groningen, Groningen, the Netherlands) for their help with the collection of tonsil tissues.

Y.Y., J.Ko., D.d.J., B.R., and M.T. performed research; Y.Y., J.Kl., I.M.N., A.D., L.V., and K.K. analyzed data; B.P. contributed germinal center B-cell samples; Y.Y., J.Kl., and A.v.d.B. designed the study and wrote the manuscript.

\section{Supplemental Data}

Supplemental material for this article can be found at http://dx.doi.org/10.1016/j.ajpath.2017.02.016.

\section{References}

1. Vardiman JW: The World Health Organization (WHO) classification of tumors of the hematopoietic and lymphoid tissues: an overview with emphasis on the myeloid neoplasms. Chem Biol Interact 2010, 184:16-20

2. Lee AI, LaCasce AS: Nodular lymphocyte predominant Hodgkin lymphoma. Oncologist 2009, 14:739-751

3. Kanzler H, Kuppers R, Hansmann ML, Rajewsky K: Hodgkin and Reed-Sternberg cells in Hodgkin's disease represent the outgrowth of a dominant tumor clone derived from (crippled) germinal center B cells. J Exp Med 1996, 184:1495-1505

4. Kuppers R, Engert A, Hansmann ML: Hodgkin lymphoma. J Clin Invest 2012, 122:3439-3447

5. Jaffe ES, Harris NL, Diebold J, Muller-Hermelink HK: World Health Organization classification of neoplastic diseases of the hematopoietic and lymphoid tissues: a progress report. Am J Clin Pathol 1999, 111: $\mathrm{S} 8-\mathrm{S} 12$

6. Bartel DP: MicroRNAs: genomics, biogenesis, mechanism, and function. Cell 2004, 116:281-297

7. Huntzinger E, Izaurralde E: Gene silencing by microRNAs: contributions of translational repression and mRNA decay. Nat Rev Genet 2011, 12:99-110 
8. Zhang B, Pan X, Cobb GP, Anderson TA: microRNAs as oncogenes and tumor suppressors. Dev Biol 2007, 302:1-12

9. Bartel DP: MicroRNAs: target recognition and regulatory functions. Cell 2009, 136:215-233

10. Calin GA, Dumitru CD, Shimizu M, Bichi R, Zupo S, Noch E, Aldler H, Rattan S, Keating M, Rai K, Rassenti L, Kipps T, Negrini M, Bullrich F, Croce CM: Frequent deletions and down-regulation of micro-RNA genes miR15 and miR16 at 13q14 in chronic lymphocytic leukemia. Proc Natl Acad Sci U S A 2002, 99:15524-15529

11. He L, Thomson JM, Hemann MT, Hernando-Monge E, Mu D, Goodson S, Powers S, Cordon-Cardo C, Lowe SW, Hannon GJ, Hammond SM: A microRNA polycistron as a potential human oncogene. Nature 2005, 435:828-833

12. Esquela-Kerscher A, Slack FJ: Oncomirs: microRNAs with a role in cancer. Nat Rev Cancer 2006, 6:259-269

13. Manikandan J, Aarthi JJ, Kumar SD, Pushparaj PN: Oncomirs: the potential role of non-coding microRNAs in understanding cancer. Bioinformation 2008, 2:330-334

14. Hammond SM: MicroRNAs as oncogenes. Curr Opin Genet Dev 2006, 16:4-9

15. van den Berg A, Kroesen BJ, Kooistra K, de Jong D, Briggs J, Blokzijl T, Jacobs S, Kluiver J, Diepstra A, Maggio E, Poppema S: High expression of B-cell receptor inducible gene BIC in all subtypes of Hodgkin lymphoma. Genes Chromosomes Cancer 2003, 37:20-28

16. Medina PP, Nolde M, Slack FJ: OncomiR addiction in an in vivo model of microRNA-21-induced pre-B-cell lymphoma. Nature 2010, 467:86-90

17. Landgraf P, Rusu M, Sheridan R, Sewer A, Iovino N, Aravin A, et al: A mammalian microRNA expression atlas based on small RNA library sequencing. Cell 2007, 129:1401-1414

18. Van Vlierberghe P, De Weer A, Mestdagh P, Feys T, De Preter K, De Paepe P, Lambein K, Vandesompele J, Van Roy N, Verhasselt B, Poppe B, Speleman F: Comparison of miRNA profiles of microdissected Hodgkin/Reed-Sternberg cells and Hodgkin cell lines versus $\mathrm{CD} 77+\mathrm{B}$-cells reveals a distinct subset of differentially expressed miRNAs. Br J Haematol 2009, 147:686-690

19. Gibcus JH, Tan LP, Harms G, Schakel RN, de Jong D, Blokzijl T, Moller P, Poppema S, Kroesen BJ, van den Berg A: Hodgkin lymphoma cell lines are characterized by a specific miRNA expression profile. Neoplasia 2009, 11:167-176

20. Navarro A, Diaz T, Martinez A, Gaya A, Pons A, Gel B, Codony C, Ferrer G, Martinez C, Montserrat E, Monzo M: Regulation of JAK2 by miR-135a: prognostic impact in classic Hodgkin lymphoma. Blood 2009, 114:2945-2951

21. Gibcus JH, Kroesen BJ, Koster R, Halsema N, de Jong D, de Jong S, Poppema S, Kluiver J, Diepstra A, van den Berg A: MiR-17/106b seed family regulates p21 in Hodgkin's lymphoma. J Pathol 2011, 225:609-617

22. Leucci E, Zriwil A, Gregersen LH, Jensen KT, Obad S, Bellan C, Leoncini L, Kauppinen S, Lund AH: Inhibition of miR-9 de-represses HuR and DICER1 and impairs Hodgkin lymphoma tumour outgrowth in vivo. Oncogene 2012, 31:5081-5089

23. Ben Dhiab M, Ziadi S, Ksiaa F, Louhichi T, Ben Gacem R, Ben Zineb A, Amara K, Hachana M, Trimeche M: Methylation of miR124a-1, miR124a-2, and miR124a-3 in Hodgkin lymphoma. Tumour Biol 2015, 36:1963-1971

24. Robertus JL, Kluiver J, Weggemans C, Harms G, Reijmers RM, Swart Y, Kok K, Rosati S, Schuuring E, van Imhoff G, Pals ST, Kluin P, van den Berg A: MiRNA profiling in B non-Hodgkin lymphoma: a MYC-related miRNA profile characterizes Burkitt lymphoma. Br J Haematol 2010, 149:896-899

25. Friedländer MR, Chen W, Adamidi C, Maaskola J, Einspanier R, Knespel S, Rajewsky N: Discovering microRNAs from deep sequencing data using miRDeep. Nature Biotechnology 2008, 26:407-415

26. Griffiths-Jones S, Grocock RJ, van Dongen S, Bateman A Enright AJ: miRBase: microRNA sequences, targets and gene nomenclature. Nucleic Acids Res 2006, 34(database issue): D140-D144

27. Kluiver J, Slezak-Prochazka I, van den Berg A: Studying microRNAs in lymphoma. Methods Mol Biol 2013, 971:265-276

28. Tan LP, Seinen E, Duns G, de Jong D, Sibon OC, Poppema S, Kroesen BJ, Kok K, van den Berg A: A high throughput experimental approach to identify miRNA targets in human cells. Nucleic Acids Res 2009, 37:e137

29. Slezak-Prochazka I, Kluiver J, de Jong D, Smigielska-Czepiel K, Kortman G, Winkle M, Rutgers B, Koerts J, Visser L, Diepstra A, Kroesen BJ, van den Berg A: Inhibition of the miR-155 target NIAM phenocopies the growth promoting effect of miR-155 in B-cell lymphoma. Oncotarget 2016, 7:2391-2400

30. Subramanian A, Tamayo P, Mootha VK, Mukherjee S, Ebert BL, Gillette MA, Paulovich A, Pomeroy SL, Golub TR, Lander ES, Mesirov JP: Gene set enrichment analysis: a knowledge-based approach for interpreting genome-wide expression profiles. Proc Natl Acad Sci U S A 2005, 102:15545-15550

31. Agarwal V, Bell GW, Nam JW, Bartel DP: Predicting effective microRNA target sites in mammalian mRNAs. Elife 2015, 4:e05005

32. Huang da W, Sherman BT, Lempicki RA: Systematic and integrative analysis of large gene lists using DAVID bioinformatics resources. Nat Protoc 2009, 4:44-57

33. Xu C, Plattel W, van den Berg A, Ruther N, Huang X, Wang M, de Jong D, Vos H, van Imhoff G, Viardot A, Moller P, Poppema S Diepstra A, Visser L: Expression of the c-Met oncogene by tumor cells predicts a favorable outcome in classical Hodgkin's lymphoma. Haematologica 2012, 97:572-578

34. Giglio S, Cirombella R, Amodeo R, Portaro L, Lavra L, Vecchione A: MicroRNA miR-24 promotes cell proliferation by targeting the CDKs inhibitors p27Kip1 and p16INK4a. J Cell Physiol 2013, 228:2015-2023

35. Lynch SM, McKenna MM, Walsh CP, McKenna DJ: miR-24 regulates CDKN1B/p27 expression in prostate cancer. Prostate 2016, 76: 637-648

36. Lorenzen JM, Kaucsar T, Schauerte C, Schmitt R, Rong S, Hubner A, Scherf K, Fiedler J, Martino F, Kumarswamy R, Kolling M, Sorensen I, Hinz H, Heineke J, van Rooij E, Haller H, Thum T: MicroRNA-24 antagonism prevents renal ischemia reperfusion injury. J Am Soc Nephrol 2014, 25:2717-2729

37. Zhang S, Zhang C, Liu W, Zheng W, Zhang Y, Wang S, Huang D, Liu X, Bai Z: MicroRNA-24 upregulation inhibits proliferation, metastasis and induces apoptosis in bladder cancer cells by targeting CARMA3. Int J Oncol 2015, 47:1351-1360

38. Zhang H, Duan J, Qu Y, Deng T, Liu R, Zhang L, Bai M, Li J, Ning T, Ge S, Wang X, Wang Z, Fan Q, Li H, Ying G, Huang D, Ba Y: Onco-miR-24 regulates cell growth and apoptosis by targeting BCL2L11 in gastric cancer. Protein Cell 2016, 7:141-151

39. Lal A, Navarro F, Maher CA, Maliszewski LE, Yan N, O’Day E, Chowdhury D, Dykxhoorn DM, Tsai P, Hofmann O, Becker KG, Gorospe M, Hide W, Lieberman J: miR-24 inhibits cell proliferation by targeting E2F2, MYC, and other cell-cycle genes via binding to "seedless" 3'UTR microRNA recognition elements. Mol Cell 2009, 35:610-625

40. Ng R, Wu H, Xiao H, Chen X, Willenbring H, Steer CJ, Song G: Inhibition of microRNA-24 expression in liver prevents hepatic lipid accumulation and hyperlipidemia. Hepatology 2014, 60: $554-564$

41. Liu R, Zhang H, Wang X, Zhou L, Li H, Deng T, Qu Y, Duan J, Bai M, Ge S, Ning T, Zhang L, Huang D, Ba Y: The miR-24-Bim pathway promotes tumor growth and angiogenesis in pancreatic carcinoma. Oncotarget 2015, 6:43831-43842

42. Zheng X, Li J, Peng C, Zhao J, Chi J, Meng X, Yun X, Li D, Yu Y, Gao M, Li Y: MicroRNA-24 induces cisplatin resistance by targeting PTEN in human tongue squamous cell carcinoma. Oral Oncol 2015, 51:998-1003 
43. Srivastava N, Manvati S, Srivastava A, Pal R, Kalaiarasan P, Chattopadhyay S, Gochhait S, Dua R, Bamezai RN: miR-24-2 controls H2AFX expression regardless of gene copy number alteration and induces apoptosis by targeting antiapoptotic gene BCL-2: a potential for therapeutic intervention. Breast Cancer Res 2011, 13:R39

44. Qin W, Shi Y, Zhao B, Yao C, Jin L, Ma J, Jin Y: miR-24 regulates apoptosis by targeting the open reading frame (ORF) region of FAF1 in cancer cells. PLoS One 2010, 5:e9429

45. Nie K, Gomez M, Landgraf $\mathrm{P}$, Garcia JF, Liu Y, Tan LH, Chadburn A, Tuschl T, Knowles DM, Tam W: MicroRNA-mediated down-regulation of PRDM1/Blimp-1 in Hodgkin/Reed-Sternberg cells: a potential pathogenetic lesion in Hodgkin lymphomas. Am J Pathol 2008, 173:242-252

46. Polyak K, Kato JY, Solomon MJ, Sherr CJ, Massague J, Roberts JM, Koff A: p27Kip1, a cyclin-Cdk inhibitor, links transforming growth factor-beta and contact inhibition to cell cycle arrest. Genes Dev 1994, 8:9-22

47. Kaelin WG Jr: E2F1 as a target: promoter-driven suicide and small molecule modulators. Cancer Biol Ther 2003, 2(4 Suppl 1):S48-S54

48. Dang CV: c-Myc target genes involved in cell growth, apoptosis, and metabolism. Mol Cell Biol 1999, 19:1-11

49. Cole MD: The myc oncogene: its role in transformation and differentiation. Annu Rev Genet 1986, 20:361-384

50. Shrivastava A, Calame K: Association with c-Myc: an alternated mechanism for c-Myc function. Curr Top Microbiol Immunol 1995, 194:273-282

51. Rui L, Emre NC, Kruhlak MJ, Chung HJ, Steidl C, Slack G, Wright GW, Lenz G, Ngo VN, Shaffer AL, Xu W, Zhao H, Yang Y, Lamy L, Davis RE, Xiao W, Powell J, Maloney D, Thomas CJ, Moller P, Rosenwald A, Ott G, Muller-Hermelink HK, Savage K, Connors JM, Rimsza LM, Campo E, Jaffe ES, Delabie J,
Smeland EB, Weisenburger DD, Chan WC, Gascoyne RD, Levens D, Staudt LM: Cooperative epigenetic modulation by cancer amplicon genes. Cancer Cell 2010, 18:590-605

52. Evan GI, Wyllie AH, Gilbert CS, Littlewood TD, Land H, Brooks M, Waters CM, Penn LZ, Hancock DC: Induction of apoptosis in fibroblasts by c-myc protein. Cell 1992, 69:119-128

53. Klefstrom J, Arighi E, Littlewood T, Jaattela M, Saksela E, Evan GI, Alitalo K: Induction of TNF-sensitive cellular phenotype by c-Myc involves p53 and impaired NF-kappaB activation. EMBO J 1997, 16: 7382-7392

54. Feuerborn A, Moritz C, Von Bonin F, Dobbelstein M, Trumper L, Sturzenhofecker B, Kube D: Dysfunctional p53 deletion mutants in cell lines derived from Hodgkin's lymphoma. Leuk Lymphoma 2006, 47:1932-1940

55. Liu Y, Abdul Razak FR, Terpstra M, Chan FC, Saber A, Nijland M, van Imhoff G, Visser L, Gascoyne R, Steidl C, Kluiver J, Diepstra A, Kok K, van den Berg A: The mutational landscape of Hodgkin lymphoma cell lines determined by whole-exome sequencing. Leukemia 2014, 28:2248-2251

56. Hoffman B, Liebermann DA: Apoptotic signaling by c-MYC Oncogene 2008, 27:6462-6472

57. Hueber AO, Zornig M, Lyon D, Suda T, Nagata S, Evan GI: Requirement for the CD95 receptor-ligand pathway in c-Myc-induced apoptosis. Science 1997, 278:1305-1309

58. Dansen TB, Whitfield J, Rostker F, Brown-Swigart L, Evan GI: Specific requirement for Bax, not Bak, in Myc-induced apoptosis and tumor suppression in vivo. J Biol Chem 2006, 281:10890-10895

59. Jiang $\mathrm{X}$, Tsang YH, Yu Q: c-Myc overexpression sensitizes Bimmediated Bax activation for apoptosis induced by histone deacetylase inhibitor suberoylanilide hydroxamic acid (SAHA) through regulating $\mathrm{Bcl}-2 / \mathrm{Bcl}-\mathrm{xL}$ expression. Int J Biochem Cell Biol 2007, 39:1016-1025 